\title{
A feral family on our doorstep
}

\author{
H Loffstadt ${ }^{1}$, RJ Nichol ${ }^{1}$, B de Klerk ${ }^{2}$
}

'Department of Psychiatry, University of the Free State, Bloemfontein, South Africa

${ }^{2}$ Department of Community Health, University of the Free State, Bloemfontein, South Africa

\begin{abstract}
A family was discovered living in isolation in the Free State region of South Africa. Certain members of this family, (the mother and three sons and a daughter) displayed primitive and ape-like behaviour, prompting the local and international press to refer to them as a feral family. The affected members of the family are presented as a case study describing how the family became isolated, their response to outside intervention and eventually how the family was "discovered". Clinical presentations are also documented as well as the therapeutic interventions used. After evaluation, the affected members of the family were shown to have various degrees of mental retardation. The words 'feral' and 'neglect' are defined and certain similar documented cases of feral children discovered previously in other regions are mentioned. The etiology of the condition is explored, discussing the effects of the environment on various aspects of neural development in children, especially referring to the lack of neuro-stimulation and other insults to the brain during the critical phase of brain plasticity. Cognitive deficits, poor mastery of language and decrease in brain size are often found in feral children. The role of a child's genetic predisposition and a paucity of environmental stimulation is also explained in the article.
\end{abstract}

Key words: Mentally disabled person; Mental retardation; Psychosocial deprivation

Received: 18.07 .05

Accepted: 16.11 .05

\section{Introduction}

Feral children: Children who have been nurtured in the wild by animals. Alternatively it also refers to children who were raised in a non-human or sub-human environment, and therefore failed to learn how to communicate in a fully human manner. ${ }^{1}$ Another definition refers to children who have been raised in complete or near complete isolation, either through abandonment or confinement. ${ }^{2}$

The failure to provide adequate care and protection for children amounts to neglect. Children can be harmed by ignorant withholding of physical, emotional and educational necessities. ${ }^{3}$ Golden, Samuels and Southall offer a similar definition for the word neglect: "Neglectful failure to supply the needs of the child. ${ }^{4}$ As such, it is a non-deliberate failure to provide the child's needs by the responsible person. This definition explicitly excludes abuse, which is always an act of commission". This type of abuse is often the result of cumulative deprivation on the part of the caregiver(s) Golden et al also explain how the child's response may also aggravate the situation as neglect can result from the failure of the child to signal its needs to the parent; as when the child is passive and does not demand attention. ${ }^{4}$ The child may become an

\section{Correspondence:}

Dr RJ Nichol, Department of Psychiatry, PO Box 339 (G66),

University of the Free State, Bloemfontein, 9300, South Africa.

email"nicholr@doh.ofs.gov.za ignored "nonentity". The resulting passivity leads from mild malnutrition to severe malnutrition and possibly death. One of the main features of severe malnutrition is passivity with flattening of affect. The child no longer communicates its needs by crying or complaining, and sustained neglect may be inevitable.

Schore too, expounds on this theme: "There is a growing body of evidence indicating that the massive caregiver misattunement of abuse and neglect induces not only intense attachment ruptures but also severe dysregulation of the infant's nascent, fragile psychobiological systems. Furthermore, this primitive avoidant strategy of dissociation that is accessed in order to cope with this trauma is known to lead to permanent alterations in the maturing brain". ${ }^{5}$

The discovery of a family who had been cut off from society for many years was sensationalized by the local and international media. Journalists were hoping to herald the identification of some new peculiar language which the members of the family utilized to communicate with each other.

This article tells the story of the family, how they were discovered, their move to an institution and further developments in their lives. Case studies of the affected children in the family are described, their interaction with one another, therapeutic interventions and attempts to re-integrate the family into the community.

Part of the dilemma facing the therapeutic team was if the family could be regarded as being "feral" or not. Various definitions of feral children are given and a several case studies of feral children that were previously discovered are mentioned. 
Emotional and physical neglect in abandoned children is discussed, especially relating to the consequences of cognitive deprivation during the critical periods of human brain development.

Finally, the interplay between genetic and environmental cues and their effects on neurodevelopment is described at a neurophysiological level.

\section{Discovery of the family}

In February 2004 a family that had been living in isolation for twenty years was found by social workers on a Free State farm. The mother (54 years), her sons (26, 22 and 18 years) and daughter (14 years) had not had any contact with the outside world during this period. They lived in a two roomed shack made of corrugated iron. The boys and their sister shared a room.

According to the father he was forced to move to the farm because his family showed strange behaviour and the community refused to accept this. They moved to the farm when the eldest boy was five years old. According to the father the children apparently developed normally until the age of eight. After which they could not walk or talk properly. He believes that his children's abnormalities were his fault, because he did not slaughter a sheep at each child's birth to appease their ancestors. He also attributed it to the fact that a sacred snake did not visit his family. According to cultural beliefs this snake has to visit each family to check that everything is in order. ${ }^{a}$

The father (who left the home daily to earn his living as a farm worker) reported that the previous owner of the farm, refused permission to allow him to integrate his children into the community, or to send them to school, or even to hospital when they were ill. The previous owner's wife said the children had been mentally ill since birth. They always fled when she and her husband took the father his wages either hiding away in the house or sitting on the wall of the animal pen.

The farm was eventually sold after the owner died. When the new owners discovered the family living on their land they were shocked. Two children were running around the shack, one leaping up and down in a frog-like manner. ${ }^{\text {b Their }}$ clothes were torn, they were dirty and in a poor physical condition. The Social Welfare Department was notified, and plans were made immediately to remove the family from the farm. The authorities reported that the children could not speak any recognizable language. One had never slept indoors. The mother and children showed signs of physical and psychological neglect. The authorities had to wait until dark and the children were in the shack before they could move the family. They gave the children bread and potato crisps to calm them down.

The mother and children were taken to a hospital in Welkom. From here they were transferred to the Free State Psychiatric Complex in Bloemfontein for further evaluation. In both hospitals the nursing staff reported the possibility of sexual behaviour

a Father: I failed my children (2004). Untitled fact sheet. Available at: http://www.news24.com/News24/South_Africa/News/0,,2-71442_1485459,00.html. [Accessed 11 October 2004]

b Feral family may never recover (2004). Untitled fact sheet. Available at: http://www thestar.co.zal

index.php?fSectionId=129\&fArticleId=356129. [Accessed 11

October 2004]. between the brothers and their mother and the brothers and their sister during the night.

It was found that the mother, daughter and one son suffered from mild mental retardation, while the other two boys were severely mentally retarded. (The couple also had another son, whose behaviour was normal. A sixth child died during childbirth).

\section{Evaluation}

During the evaluation period, the children were interviewed by a psychiatrist, psychologists and occupational therapists. In the occupational therapy sessions, the children received intensive therapy to help them socialize in order to assist their integration back into society. They were also taught basic life skills.

Although it was impossible to do formal psychometric testing, the psychological evaluation was done by a senior psychologist using his clinical judgement. The daughter was diagnosed as having mild mental retardation; The youngest of the three brothers as having mild to moderate mental retardation and the two older brothers as having sever mental retardation.

Although the mother and four children spent almost their entire day together there was apparently very little constructive interaction between them. The members of the family communicated with gestures and a paucity of non-verbal communication. The daughter and her eldest brother appeared mute, while the youngest brother and the middle brother had a vocabulary of one word and three words respectively.

All four children had a restricted attention span and were not able to concentrate for long, being easily distracted by external stimuli. They had a shallow affect and felt threatened in the presence of strangers but still displayed a restricted range of emotions. The eldest son had a permanently downcast gaze.

Regarding physical appearance; the three young men stood and walked in a hunched position. All four children appeared anaemic (possibly due to an iron deficiency anaemia). The daughter was able to eat and drink with utensils, but like her brothers she needed assistance with dressing, personal hygiene and bathing. They tended to follow the ward routine passively with little internal motivation.

\section{Progressafter six months in the ward}

The cornerstones in treatment were the interventions by the Occupational Therapy and Nursing departments of the hospital. The main emphases in management were individual stimulation and mastery of skills necessary for integration back into society. The daughter soon learnt basic tasks such as making tea and porridge, and dressing herself. She remained shy but gradually her interaction with other patients increased. She spoke in whispers using monosyllables and a limited vocabulary. The youngest son mastered the use of eating utensils. He also learnt to use a toilet. He needed supervision while dressing or bathing. He played soccer with his brothers but showed no increase in his vocabulary. Similarly, the middle brother needed help with dressing and bathing. He learnt to use a spoon but could not use a cup alone. He was able to show emotion (smiled) when playing soccer but remained with a poor vocabulary. The eldest of the three brothers also retained a poor vocabulary. He enjoyed soccer and interacted with his brothers. He learnt to wash and dress himself without assistance. 


\section{Genetic studies}

Initially inappropriate physical (possibly sexual) behaviour was noticed by the ward staff occurring between the young men and their mother and possibly the brothers and the sister. Genetic studies were performed to determine the paternity of the daughter and also to establish if a cause of the children's mental handicap could be determined. No abnormalities could however be detected.

A house was allocated to the Majola family in a town in the vicinity of their previous dwelling. Mrs. Majola was re-united with her husband. Their daughter was discharged from hospital and their sons will also be re-integrated into society. The family receives home visits by a registered nurse and a social worker in the community.

\section{Feral children}

The term "feral" means wild or undomesticated. When feral children enter human society after their developmental years in isolation, they often continue to be seriously retarded. ${ }^{6}$

Researchers seek to find answers to the question of whether the abnormalities in feral children existed before their removal from society, or if they develop in this way because of their isolation.

There have been over forty well-documented cases of feral children over the past few centuries. ${ }^{\text {? }}$

The first famous example was 'Wild Peter", who was captured near Hanover, Germany in 1724, when he was about twelve years old. He behaved like a wild animal, eating raw birds and vegetables, and when threatened, he sat on his haunches or on all fours looking for opportunities to escape. Peter became the possession of King George I of England, where he lived the rest of his life. He never learned to talk, showed complete indifference to money or sex, and was never seen laughing. He died in 1785. ${ }^{\circ}$ Perhaps Pervasive Developmental Disorder would have been an alternative diagnosis for Peter?

Unlike Peter, a young man named Kaspar Hauser, was found in Germany in 1828, had apparently been locked up in isolation for an extended period, but without being deprived of human care. He was 17 years old, but had the mentality of a child of three, Hauser was re-educated over the next five years, regaining many of the faculties that have been stunted by extreme social and sensory deprivation, to the point where he could communicate verbally although his speech was substandard. ${ }^{8}$

\section{The critical period}

Many feral children are found to be mentally retarded and physically small for their age depending on how young they were when originally abandoned. The nervous system of young children is malleable and depends on experience to shape the behaviour and skills needed for life. If abandoned while very young, they may never make up for lost experience. This is known as the critical period of brain plasticity. The idea of critical periods teaches us that for some aspects of brain development, timing of environmental input is crucial, and that important abilities will be lost or diminished if stimulation does not occur at the right time. ${ }^{9}$ The mastery of language skills is a good example of how neglect in the critical period can influence development. If language is not acquired during this period of development, the child may never be able to learn more than a very basic vocabulary. This confirms

c. The world of strange phenomina: Forteam Times (2002). Wild things. Available at: http://207.206.205.129/articles/ 161_feralkids.shtml. [Accessed 11 October 2004] previous findings reported by Bornstein that infants who processed visual information more efficiently and had mothers who more frequently encouraged them to attend to properties, objects and events in the home environment in the first six months after birth excelled in verbal development during their second year and scored higher on a conventional psychometric assessment of intelligence at four years. ${ }^{10}$ Bornstein further noted that infants and mothers also mutually influence one another during development through their continuing transactions. For example, a significant concurrent association between infant habituation and maternal encouraging attention at four months, or, more clearly, infant attention style at four months influences maternal didactics measured eight months later. ${ }^{10}$ Bornstein presupposes this explains finding in the United States of America that otherwise disadvantaged infants adopted into advantaged families before their six-month birthday score higher tests of intelligence and achieve better in school than do children adopted after infancy. ${ }^{10}$ Duyme, Dumaret and Tomkiewicz studied French children who were exposed to maternal deprivation prior to adoption. They replicated the findings of other longitudinal studies that mentally deficient and environmentally deprived children who continue to receive no treatment were likely to decline in Intelligence Quotient until early and middle adolescence. ${ }^{11}$

Powell, Baker-Henningham, Walker, Gernay and GranthamMcGregor found that previously undernourished Jamaican children had increased scores on the Griffiths mental development scales with improved hearing and speech, and hand and eye coordination after stimulation was included in Primary Health Care visits to their mothers. No improvements were noted in locomotor subscales compared to the control group of children. ${ }^{12}$ These findings concur with the clinical evaluation of the Majola children where gross motoric development was not impaired.

Non-invasive scanning techniques carried out on contemporary feral children shows their brains can be 30\% smaller than normal. ${ }^{13}$ It is accepted that psychological factors "prune" or "sculpt" neural networks in specifically the postnatal frontal, limbic and temporal cortices Schore in his book "Affect dysregulation and disorders of the self" proposes that excessive pruning of cortical-subcortical limbic-autonomic circuits occurs in early histories of trauma and neglect, and that this severe growth impairment represents the mechanism of the genesis of a developmental structural defect. Maternal neglect is the behavioural manifestation of maternal deprivation, and this alone or in combination with paternal physical abuse is devastating to developing limbic systems. Excessive pruning is known as parcellation or the activity-dependent winnowing of surplus circuitry. Parcellation has previously been described in terms of hyperactivation of the dopamine-sensitive excitotoxic NMDAsensitive glutamate receptor, a critical site of synapse neurotoxicity and elimination during early development. As opposed to this hypermetabolic response, cortical release triggers hypometabolism, a condition that enhances the toxicity of excitatory neurotransmitters. During critical periods, dendritic spines, potential points of connections with other neurons, are particularly vulnerable to long pulses of glutamate that trigger severely altered calcium metabolism and therefore "oxidative stress" and apoptic damage. It is known that stress increases levels of oxidative damage to brain lipid membranes, protein and DNA, including mitochondrial DNA, that stress increases levels of excitatory amino acids such as glutamate in the prefrontal cortex, and that excitotoxins can destroy orbitofrontal neurons. 


\section{The impact of neglect on neural development}

Developmental experiences determine the organizational and functional status of the mature brain, and, therefore adverse events can have a tremendous negative impact on the development of the brain. ${ }^{14}$ Although most of the literature on feral children concentrates on language development, there are many other aspects of cognitive development that are affected by neglect, abuse and malnutrition.

In the human brain, structure and function have developed together. As we have a hierarchy of increasingly complex functions related to optimal functioning, our brain has evolved a hierarchical structural organization. This hierarchy starts with the lower, simpler brainstem areas and increases with complexity up through the new cortex. ${ }^{13}$ The specific dysfunction will depend upon the timing of the insult (e.g. at stage two where the cortex develops maximally), the nature of the insult (e.g. a lack of sensory stimulation due to neglect) and the pattern of the insult (e.g. a chronic experience). Shore explains that the right hemisphere is specifically impacted by early attachment experiences - in fact these object relational affect-communicating experiences facilitate its maturation. On the other hand, a history of cumulative relational trauma, or of frank abuse and neglect, represents a growthinhibiting environment for the maturation of the right brain. The insecurely attached infant's all-too-common stressful experiences with a caregiver who chronically initiates but poorly repairs intense and long-lasting dysregulated states are incorporated in rightbrain long-term autobiographical memory as a pathological internal object relation, an interactive representation of a dysregulated-self-interaction-with-a-misattuning-object. Shore quotes Gaensbauer as stating 'The clinical data, re-inforced by research findings indicate that preverbal children, even in the first year of life, can establish and retain some form of internal representation of a traumatic event over significant periods of time". Shore also quotes Joseph by adding "Neuroscientists describe early emotional learning occurring in the right hemisphere unbeknownst to the left; learning and associated emotional responding may later be completely unaccessible to the language centers of the brain" "5,14

The effects of the childhood environment interact with all the processes of neurological development. ${ }^{15}$ These processes include neurogenesis, migration, differentiation, apoptosis, arborization, synaptogenesis, synaptic sculpting and myelination. These neurodevelopmental processes are dependant upon genetic and environmental cues e.g. neurotransmitters, neuromodulators, neurohormones and other morphogenes. Disruption of the pattern, timing or intensity of these cues can lead to abnormal neurodevelopment and severe dysfunction, since the developmental experiences determine the organizational and functional status of the mature brain. How an individual functions in his environment, is dependant upon the expressions of a unique combination of genes available to the human species. What we become depends upon how our experiences shape the expressions of specific genes we have. For instance we humans have the genes to make forty sounds and have the experiences to turn this genetically determined capacity into language, but a child raised in an environment without language cannot - despite the genetic potential express this lingual potential fully.

Neglect is the absence of critical organizing experiences at key times during development. The needs of a child shift during development. What may be neglectful at one stage, may not be in another. Neglect during early childhood supports a neuroarcheological view of adverse childhood events. The earlier and more pervasive the neglect is, the more devastating the developmental problems of the child.

\section{Conclusion}

We may wonder: were the children found on the Free State farm mentally handicapped at birth, or was their condition due to disruption of their neurodevelopmental processes at critical stages due to neglect? So too, if Mrs. Majola had been more capable of raising her offspring under optimal conditions with the necessary assistance of an extended family, perhaps the affected children might have shown a very different degree of adjustment and emotional and cognitive growth. Perhaps, according to the work of Bornstein ${ }^{10}$ a different mother would have been more receptive to the emotional cues shown by her infants, which in turn would have enhanced their stimulation rather than the resultant apathetic flattening of affect.

We may never be in a position to answer these questions. It is clear that an optimal physical and psychological nurturing environment, is essential for children to reach their best level of functioning. Neglect during childhood alters a child's potential, and thus the whole community is disadvantaged.

\section{References}

1. McCrone J. Feral children. Lancet-neurology 2003; 2 (2):132.

2. Chambers TL. Feral children. Journal of the Royal Society of Medicine 2002;11:576

3. Sadock BJ, Sadock VA. Comprehensive textbook of psychiatry: Lippincott Williams and Wilkens, Philadelphia 2003; 2878.

4. Golden MH, Samuels MP, Southall D.P. Arch Dis Child 2003; 88: 105-107.

5 Schore AN. Affect regulation and the repair of self. New York: WW.Norton \& Company, 2003.

6. Gayle Encyclopedia of Childhood and Adolescence: Feral Children (2004). Untitled fact sheet. Available at: http://www.findarticles.com/p/ articles/mi_g2699/is0001/ai_2699000132 [Accessed 11 October 2004].

7. Struve U. A myth becomes reality: Kaspar Hauser as messianic wild child. Studies in 20th Century Literature 1998; 22:273-294.

8. Simon N. Kaspar Hauser's recovery and autopsy: A perspective on neurological and sociological requirements for language developmental, Journal of Autism and Childhood Schizophrenia 1978; 8:209-217.

9. Andreasen NC. Brave New Brain - Conquering Mental Illness in the Era of the Genome. Oxford: Oxford University Press 2001.

10. Bornstein MH. How infant and mother jointly contribute to developing cognitive competence in the child. Proc Natl Acad Sci,USA 1985; 74707473.

11. Duyme M,Dumaret A,Tomkiewicz S. How can we boost IQs of "dull children"?: A late adoption study Proc Natl Acad Sci USA 1999; 87908794.

12 Powell C, Baker-Henningham H, Walker S, Gernay J, GranthamMcGregor S. Feasibility of integrating early stimulation into primary care for undernourished Jamaican children: cluster randomised controlled trial BMJ, doi:10.1136/bmj.38132.503472.\&C(published 24 June 2004).

13. Perry BD, Pollard RA. Homeostasis, stress, trauma and adaptation: A neurodevelopmental view of childhood trauma. Child and Adolescent Psychiatric Clinics of North America 1998;7:33-51.

14. Schore AN. Affect dysregulation and disorders of the self. New York: WWNorton \& Company, 2003

15. Perry BD, Pollard RA, Blakeley TL, Baker WL and Vigilante W. Childhood trauma, the neurobiology of adaptation and use-development of the brain: How states become traits. Infant Mental Journal 1995; 16:271-291. 